\title{
Francisco Gutiérrez Sanín, El orangután con sacoleva. Cien años de democracia y represión en Colombia (1910-2010),
} Bogotá:IEPRI, 2014, 526 pp.

\section{Por: Claudia Ximena Serna García}

Docente de la Institución Educativa Tulio Enrique Tascón Chambimbal (Buga). Licenciada en Etnoeducación y Especialista en Educación, Cultura y Política de la Universidad Nacional Abierta y a Distancia (UNAD). Estudiante de la de Maestría en Historia en la Universidad del Valle. Correo electrónico:ximena.sernag@gmail.com.

La democracia en Colombia tiene un carácter curioso. Si bien ésta se engalana frente a otros países por su aparente prolongación en el tiempo, sus condiciones no demuestran que en realidad lo sea, puesto que las características que la determinan no corresponden a lo que hace parte de procesos democráticos ni actuales ni pasados.

Motivado por describir y explicar por qué Colombia ha "sufrido esta coexistencia estable entre institucionalidad democrática y represión; y qué tan específico es el fenómeno en una perspectiva comparada"1 el sociólogo y antropólogo Francisco Gutiérrez Sanín, director del Observatorio sobre Restitución de Tierras, presenta su libro El orangután con sacoleva. Cien años de democracia y represión en Colombia (1910-2010).

Para desarrollar su objetivo, el autor hace uso de fuentes como la prensa, la información sobre diseños institucionales relativos a la configuración del Estado y las relacionadas con el conflicto y la seguridad, literatura secundaria y evaluaciones de contemporáneos, archivos personales, correspondencia, expedientes judiciales y otros medios como la información cuantificable que hace presencia a partir de 1980, información a nivel de agencias de seguridad y de los ministerios a los que están adscritas ${ }^{2}$.

Gutiérrez Sanín logra presentar una narrativa que comprende un marco temporal de un siglo: 1910-2010, cuyos límites están determinados por "el reinicio de la política largamente competitiva en Colombia", y la terminación de "la que probablemente haya sido la presidencia más popular de nuestra historia". El autor considera que su obra es "una oportunidad para pensar nuestros problemas desde una perspectiva comparada, pero dialogando con la rica tradición de nuestras ciencias

1 Francisco Gutiérrez Sanín, El orangután con sacoleva. Cien años de democracia y represión en Colombia (1910-2010) (Bogotá: IEPRI, 2014), 12.

2 Francisco Gutiérrez Sanín, El orangután con sacoleva, 20.

3 Francisco Gutiérrez Sanín, El orangután con sacoleva, 20. 
sociales"4. Es necesario anotar que en diferentes partes del libro, Gutiérrez Sanín se refiere a las limitaciones con las que se encontró al momento de acceder a las fuentes cuantificables, especialmente aquellas con fecha previa a 1980.

El orangután con sacoleva está dividido en tres partes y once capítulos. En la introducción del libro, Gutiérrez Sanín describe de manera detallada cada una de las temáticas que abordará en cada capítulo y la metodología con la que construyó su estudio y bajo las cuales llegó a sus conclusiones. El libro estudia, desde diferentes perspectivas, la historia de la violencia en Colombia, al contrastar condiciones geográficas, históricas y estadísticas en los órdenes internos y externos de la nación. No podría esperarse menos de un autor cuya formación profesional comprende la antropología, la matemática aplicada, el análisis de problemas políticos, económicos e internacionales contemporáneos y las ciencias políticas. Sus temas de investigación se han centrado en la paz, el posconflicto, la represión, la violencia y la participación ciudadana, entre otros. Su condición de colombiano le permite tener una percepción muy propia de las dinámicas que en su país se gestan. De igual manera, el hecho de estar en constante interacción con el medio académico desde otros países le permite formarse una idea que tiene en cuenta variados escenarios con contrastes que desde su condición de antropólogo ayudan a explicar formas de actuar de las partes inmersas en el conflicto.

En principio, la comparación que Gutiérrez Sanín hace entre la democracia de Colombia y un orangután elegante puede parecer una manera cruel y cruda de describir el proceso democrático en el país. Cruel y cruda pero, a la vez, consistente, pues si bien la democracia como modelo de gobierno determina algunas dinámicas de gobernabilidad y toma de decisiones, su elección no determina que estas condiciones estén dadas y para el caso colombiano, muy por el contrario, las condiciones sociales no están dadas para que la democracia tenga unos resultados efectivos y que redunden en la consolidación de un Estado fuerte, sino que éste se ha mostrado como un régimen democrático con características propias que lo hacen diferente de otros países en vía de desarrollo o tercermundistas. El contraste del orangután con sacoleva con la democracia colombiana resulta apropiado al evidenciar las contradicciones de una constante vulneración de la población civil o guerra contra el pueblo y algunas intenciones de darle pertinencia en la participación democrática de la población.

Ahora bien, aspectos como la represión, el ataque a la población civil, la lucha bipartidista, y la prolongación de las disputas territoriales por el poder, hacen que en Colombia se viva en condiciones similares a las de una dictadura en las que la represión por parte del Estado conducen a que los esquemas de seguridad sean asumidos por la población civil, por grupos financiados por el mismo Estado como los paramilitares, por grupos de oposición como la guerrilla y por grupos independien-

4 Francisco Gutiérrez Sanín, El orangután con sacoleva, 20. 
tes como las bandas criminales. Así, los efectos de un Estado débil se ven materializados en la privatización de la seguridad, los derechos de propiedad sobre la tierra inequitativos y mal especificados y el centrismo violento que aunque hayan acudido a estrategias como las adoptadas por el Frente Nacional, conservan una ambición por los partidos políticos de dominar a su opositor y no de convivir en escenarios democráticos con ellos. Si bien en Colombia existe el derecho al voto, esta condición no es garantía de que los procesos democráticos tengan la importancia que realmente deberían tener.

El autor establece una comparación entre Colombia y algunos países vecinos. De esta analogía concluye que, si bien los vecinos han tenido confrontaciones, largos periodos dictatoriales y manifestaciones de violencia, sus condiciones actuales se caracterizan por cierto nivel de estabilidad. Para Gutiérrez Sanín en Colombia esto no ha sido posible, pues a al proceso democratización del régimen colombiano de 1991 siguió un aumento notable en los niveles de represión, en el que algunos de los diseños institucionales más obviamente homicidas fueron promovidos o al menos tolerados por líderes centristas, en medio de procesos de paz o de democracia significativa.

Esta afirmación coincide con el análisis del sociólogo e historiador Miguel Ángel Centeno, profesor de la Universidad de Princeton, quien en su libro Sangre y Deuda. Ciudades, Estado y construcción de nación en América latina, expresa que los recientes Estados independientes de la región - exceptuando quizá a Chile y Paraguay- "no pudieron definir fácilmente la nación que debían representar" ya que "Debido a que la construcción de dicha identidad estaba tan cargada de conflicto político, los Estados dudaban seguir los esfuerzos de 'construcción de nación’ de las contrapartes de Europa occidental" ${ }^{2}$. En ese mismo sentido, Centeno hace una exposición sobre lo que denomina "guerras totales" y "guerras limitadas", las cuales tienen diferentes consecuencias. Las primeras producen Estados más ricos y poderosos, mientras que las segundas rara vez dejan legados institucionales positivos y con frecuencia tienen costos a largo plazo $^{6}$. Resulta pertinente coincidir estas afirmaciones con las de Gutiérrez Sanín cuando dice "es difícil dejar de caracterizar a la República Liberal como una apertura sustantiva del régimen, con un claro contenido modernizador, pero bajo su sombrilla los ataques contra la población civil se mantuvieron en un nivel alto"7

Las anteriores afirmaciones me llevan a concluir que en Colombia las condiciones históricas respecto a la conformación del Estado continúan en crisis. Esto se refleja en un Estado débil que fomenta constantes ataques a la población civil, luchas partidistas, clientelistas, de corrupción y clientelismo para el acceso al poder. A manera de ejemplo, el acceso a la tierra se da en condiciones

\footnotetext{
5 Miguel Ángel Centeno, Sangre y Deuda. Ciudades, Estado y construcción de nación en América latina (Bogotá: Universidad Nacional de Colombia, Instituto de Estudios Urbanos, 2014).

6 Miguel Ángel Centeno, Sangre y Deuda, 54.

7 Francisco Gutiérrez Sanín, El orangután con sacoleva, 437.
} 
de desigualdad y prerrogativa por parte de los monopolios, lo que genera condiciones de desigualdad teniendo en cuenta que la población con bajos recursos no logra ser un referente de competencia lo que constituye un medio de represión.

Sobre la explicación de la represión colombiana, Francisco Gutiérrez Sanín incluye un muestrario en el que considera que el cierre del sistema (tenemos una democracia bloqueada, cerrada o excluyente), la exclusión social (debate entre desigualdad/exclusión y traducción de unidades de exclusión en términos de violencia política y represión), las explicaciones culturalistas ("Colombia es violenta porque sus normas y valores lo son”) y la debilidad del Estado (la relación de estado débil y violencia es estructural en las Ciencias Sociales en Colombia). Según el propio autor explica, lo que intentó hacer fue comprender y caracterizar “nuestra anomalía”, lo que lo llevó a dejar por fuera "aspectos del análisis de la represión que, aunque no necesarios para su explicación, son extremadamente relevantes, en términos analíticos y de política (la creación de las inercias institucionales; las interacciones entre los Gobiernos y sus oposiciones)" $"$.

El orangután con sacoleva se presenta como una crítica a los métodos de democracia establecidos en Colombia que se caracterizan por grandes incoherencias ideológicas y la búsqueda del beneficio de una población minoritaria de la sociedad, población llamada por algunos como oligarquía y que presenta acciones en las que la constante es la agresión y vulneración a la población civil a través de homicidios, exterminio de comunidades rurales, ataque a grupos étnicos, desplazamiento de la población campesina, acceso carnal violento a las mujeres por parte de grupos beligerantes como guerrillas, paramilitares y hasta ejército, la defensa de la propiedad privada a costa de la fundación de grupos con y sin el aval del Estado materializados en guerrillas, paramilitares, bandas criminales y delincuencia común. Estas realidades hacen que el la metáfora del Orangután con Sacoleva represente un Estado en crisis que no ha logrado consolidarse en correspondencia a sus hermanos latinoamericanos que pese a sus crisis y mayores presencias de dictadura manifiesta, se estructuraron en función de su proyecto de nación.

8 Francisco Gutiérrez Sanín, El orangután con sacoleva, 456. 